\title{
The measurement of nose dimensions through the three-dimensional reformation images after nasal bone fracture
}

Seung Bin Jang, Dong Gil Han

Department of Plastic and Reconstructive Surgery, Catholic University of Daegu School of Medicine, Daegu, Korea
Background: After closed reduction, patients are sometimes concerned that their external nasal shapes have changed. The aim of this study was to investigate and explain changes in nasal shape after surgery through objective photogrammetric anthropometry measurements taken through three-dimensional (3D) reformed computed tomography (CT) images.

Methods: Our study included 100 Korean patients who underwent closed reduction of isolated nasal bone fracture from January 2016 to June 2017. Using the ruler tool in Adobe Photoshop CS3, we measured preoperative and postoperative nasal base heights, long nostril axis lengths, both nasal alar angles, and amount of nasal deviation through the 3D reformation of soft tissue via CT scans. We then compared the dimension of nose.

Results: The amount of postoperative correction for nasal base height was $1.192 \mathrm{~mm}$. The differences in nostril length between each side were found to be $0.333 \mathrm{~mm}$ preoperatively and 0.323 $\mathrm{mm}$ postoperatively. The differences in the nasal alar angle between each side was $1.382^{\circ}$ preoperatively and $1.043^{\circ}$ postoperatively. The amount of nasal deviation was found to be $5.248 \mathrm{~mm}$ preoperatively and $1.024 \mathrm{~mm}$ in postoperatively.

Conclusion: After the reduction of nasal bone fractures, changes in nasal dimensions were noticeable in terms of nasal deviation but less significant in nasal tips, except for changes in nasal alar angles, which were notable.

Keywords: Nasal bone / Nose / Outcomes / Surgery

\section{INTRODUCTION}

The nose is located in the center of the face, and the incidence of nasal bone fractures is on the rise [1-4]. Isolated nasal bone fractures usually require closed reduction procedures, and nasal bone fracture patients often have great interest in the appearances of their noses following the operation. After surgery, these patients examine their noses carefully to determine whether their nasal shapes have been changed.

\section{Correspondence: Dong Gil Han}

Department of Plastic and Reconstructive Surgery, Catholic University of Daegu School of Medicine, 33 Duryugongwon-ro 17-gil, Nam-gu, Daegu 42472, Korea E-mail: dghan1001@cu.ac.kr

Received September 14, 2018 / Revised December 7, 2018 / Accepted December 8, 2018
In the past, many studies have measured the nose of healthy Korean subjects [5-8]. However, few studies have examined the nasal anthropometry of subjects who have experienced nasal bone fractures. This study aimed to investigate and explain changes in nasal shapes before and after surgery through objective photogrammetric anthropometry measurements taken through the three-dimensional (3D) reformation of computed tomography (CT) images.

\section{METHODS}

\section{Patient evaluation}

A database of patients who experienced nasal bone fractures 
between January 2016 and June 2017 was reviewed, and 100 patients over 20 years old who had isolated nasal bone fracture and underwent closed reduction procedure were included in the study. Patients who had congenital facial anomalies or had undergone any previous nasal surgeries were excluded. Clinical evaluations collected data on patient age, sex, and objective changes to the nose (both preoperatively and postoperatively) as measured by the height of the nasal base, length of the long nostril axis, the nasal alar angle and the amount of nasal deviation.

\section{Surgical technique and time of CT scans}

Closed reduction procedures were performed on all subjects while under general anesthesia. Pre-existing septal fracture or deviation was reducted conservatively. Following the reduction, Vaseline gauze was packed into the dorsal nasal cavity and Merocel (Medtronic Xomed, Jacksonville, FL, USA) was placed in the nasal airway with an external nasal splint. Examinations of preoperative CT scan were taken in day of injury visiting emergency room, and closed reductions were done about a week after the injuries. Examinations of postoperative CT scans were taken approximately 6 hours after the operations with removal of Merocel and nasal packings [9].

\section{Photogrammetric nasal anthropometry}

Nasal anthropometry was examined using the ruler tool in Adobe Photoshop CS3 (Adobe Inc., San Jose, CA, USA) through the $3 \mathrm{D}$ reformation of soft tissue made from $\mathrm{CT}$ scans that were taken with non-enhanced facial bone CT images with $2 \mathrm{~mm}$ sections (Dual 128-channel CT SOMATOM Definition Flash; Siemens Industries, Munich, Germany).

For objective measurements of nasal tip, the positions of the nasion and pronasale were adjusted to the same point in the

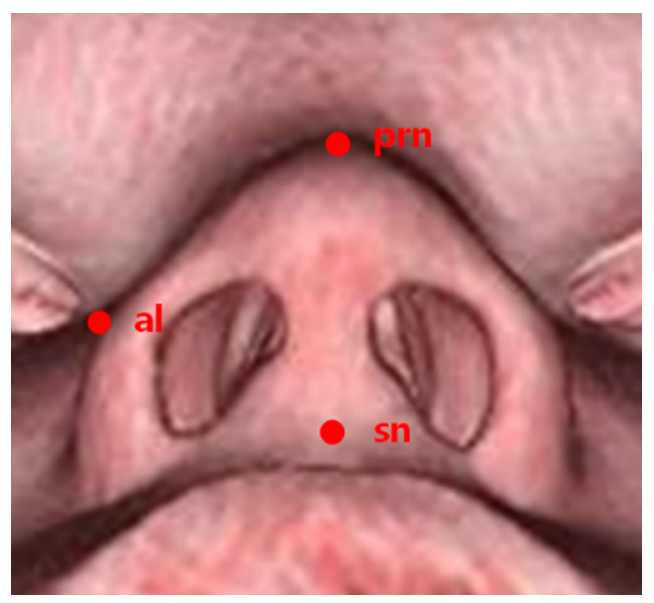

Fig. 1. Base view of the nose in which the nasion and pronasale are at the same point. prn, pronasale; al, alare; sn, subnasale. basal view, and then, the height of the nasal base from the pronasale to subnasale, the nostril length of the long axis, and the nasal alar angles on both the right and left sides were also measured. Additionally, the changes between the right and left nostril lengths with the nasal alar angle were measured (Figs. 1, 2).

For measuring the nasal deviation, according to Frankfort horizontal line, amount of nasal deviation was measured on frontal view. We drew a vertical line from the midpoint of the glabella to the midpoint of the upper lip and marked the most prominent point of nasal dorsal deviation. Amount of nasal deviation was measured according to the length from the vertical midline to the point of most deviation on nasal dorsum (Fig. 3) [10].

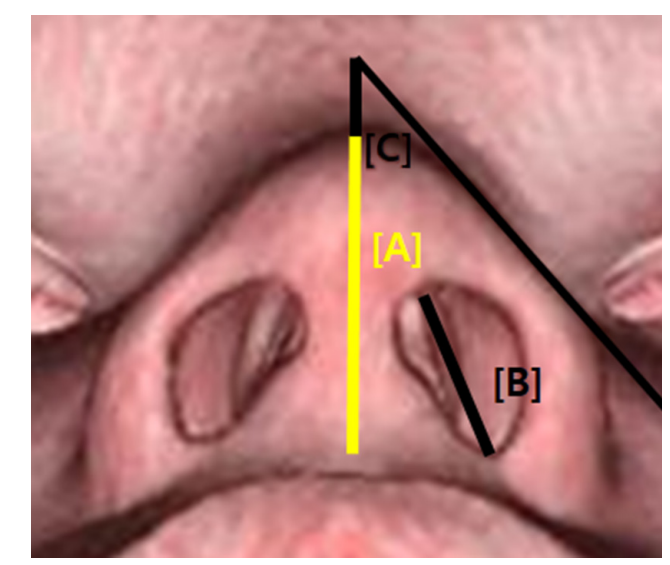

Fig. 2. Measurement of the nose. The measurement of nose was done by adjusting when the nasion and pronasale are at the same point. A, height of the nasal base from the pronasale to subnasale; $\mathrm{B}$, length of the long nostril axis; $\mathrm{C}$, nasal alar angle, which is between the most prominent point of the alar wing and midline.

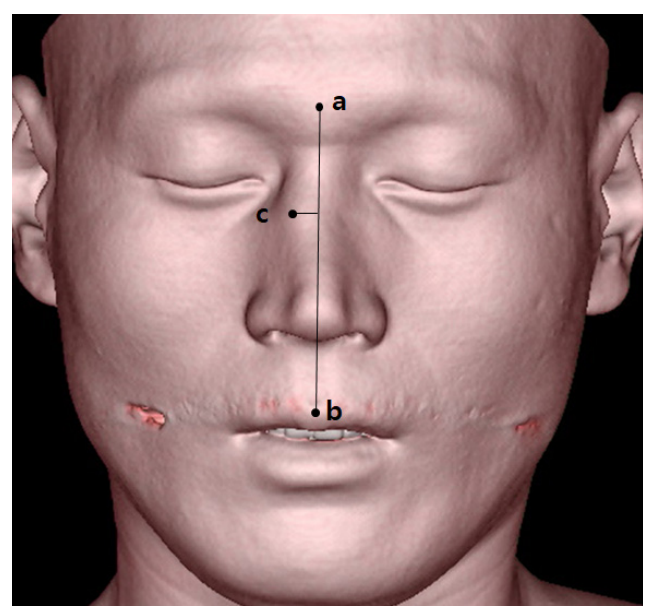

Fig. 3. Amount of nasal deviation. For objective measurement of nasal deviation, according to Frankfort horizontal line, amount of nasal deviation was measured on frontal view. Amount of nasal deviation was measured by length from midline to point C. a, midpoint of the glabella; b, midpoint of the upper lip; c, most prominent point of deviation. 
Table 1. Comparison between preoperative and postoperative measurements of the nasal tip

\begin{tabular}{lccc}
\hline Variable & Preoperative & Postoperative & Difference \\
\hline Height of the nasal base $(\mathrm{mm})$ & 20.192 & 21.384 & 1.192 \\
\hline Length of the right long nostril axis $(\mathrm{mm})$ & 11.929 & 12.629 & 0.700 \\
Length of the left long nostril axis $(\mathrm{mm})$ & 12.262 & 12.952 & 0.690 \\
Right nasal alar angle $\left(^{\circ}\right)$ & 41.183 & 40.338 & 0.845 \\
Left nasal alar angle $\left(^{\circ}\right)$ & 42.565 & 41.381 & 1.184 \\
\hline
\end{tabular}

Table 2. Length difference of the long nostril axis between right and left side

\begin{tabular}{lc}
\hline Variable & Length difference $(\mathrm{mm})$ \\
\hline Preoperative & 0.333 \\
Postoperative & 0.323 \\
Correction amount & 0.010 \\
\hline
\end{tabular}

\section{RESULTS}

\section{Demographics}

The 100 patients were all over 20 years old; 70 were male and 30 were female. The mean age was 41.08 years old.

\section{Photogrammetric anthropometry of the nose}

In terms of nasal base height, the mean preoperative value was $20.192 \mathrm{~mm}$ and the mean postoperative value was $21.384 \mathrm{~mm}$ (Table 1). The difference between the preoperative value and postoperative one was $1.192 \mathrm{~mm}$ (Table 1). The mean preoperative value for the length of the long axis of the right nostril was $11.929 \mathrm{~mm}$, and its postoperative value was $12.629 \mathrm{~mm}$; the mean preoperative value of the long axis of the left nostril was $12.262 \mathrm{~mm}$, and its postoperative value was $12.952 \mathrm{~mm}$ (Table 1).

The difference in the diagonal length of nostril comparing both sides was $0.333 \mathrm{~mm}$ preoperatively and $0.323 \mathrm{~mm}$ postoperatively (Table 2). The mean value for the right nasal alar angle was $41.183^{\circ}$ preoperatively and $40.338^{\circ}$ postoperatively. For the left nasal alar angle, the mean preoperative value was $42.565^{\circ}$ and the postoperative value was $41.381^{\circ}$ (Table 1 ).

The mean deviation in the alar angle between both sides were found to be $1.382^{\circ}$ preoperatively and $1.043^{\circ}$ postoperatively (Table 3). The mean amount of nasal deviation were found to be $5.248 \mathrm{~mm}$ preoperatively and $1.024 \mathrm{~mm}$ postoperatively. The mean correction value of nasal deviation was found to be 4.224 $\mathrm{mm}$ (Table 4).

\section{DISCUSSION}

In cases of isolated nasal bone fractures, it is common to perform a closed reduction. Patients with nasal bone fractures are
Table 3. Deviation of the nasal alar angle between right and left side

\begin{tabular}{lc}
\hline Variable & Nasal alar angle $\left(^{\circ}\right)$ \\
\hline Preoperative & 1.382 \\
Postoperative & 1.043 \\
Correction amount & 0.339 \\
\hline
\end{tabular}

Table 4. Amount of nasal deviation

\begin{tabular}{lc}
\hline Variable & Nasal deviation $(\mathrm{mm})$ \\
\hline Preoperative & 5.248 \\
Postoperative & 1.024 \\
Correction amount & 4.224 \\
\hline
\end{tabular}

Amount of nasal deviation: length from vertical midline to most deviation point of nasal dorsum.

often curious about potential changes to their nasal shape following the operation. After experiencing a prominent nasal deformity caused by trauma, patients are usually highly concerned about returning to their prior nasal appearance after surgery. Although many studies have measured noses in healthy Korean subjects, few have compared changes between preoperative and postoperative nose shapes in patients with nasal bone fractures.

This study aimed to investigate and explain changes in nose before and after surgery of nasal bone fracture through nasal anthropometry. A direct anthropometry method is ideal, but this requires considerable time and repeated measurements. Therefore, many previous studies used indirect anthropometry methods, such as those using standardized clinical photography [11].

However, there may be intractable value discrepancies between direct and indirect anthropometry methods. Recently, it has been possible to take photogrammetric anthropometric measurements through 3D image from soft tissue reformation as result of the increased utilization and quality of CT scanning. Many studies have analyzed the accuracy of anthropometry based on CT imagery. Today, it is commonly agreed that indirect anthropometry through $3 \mathrm{D}$ reformation is no different than direct anthropometry $[12,13]$. Thus, we evaluated nasal shape through indirect anthropometry using a 3D reformed soft tissue image. As most patients are more interested in their external nasal appearance than in how their reduction was per- 

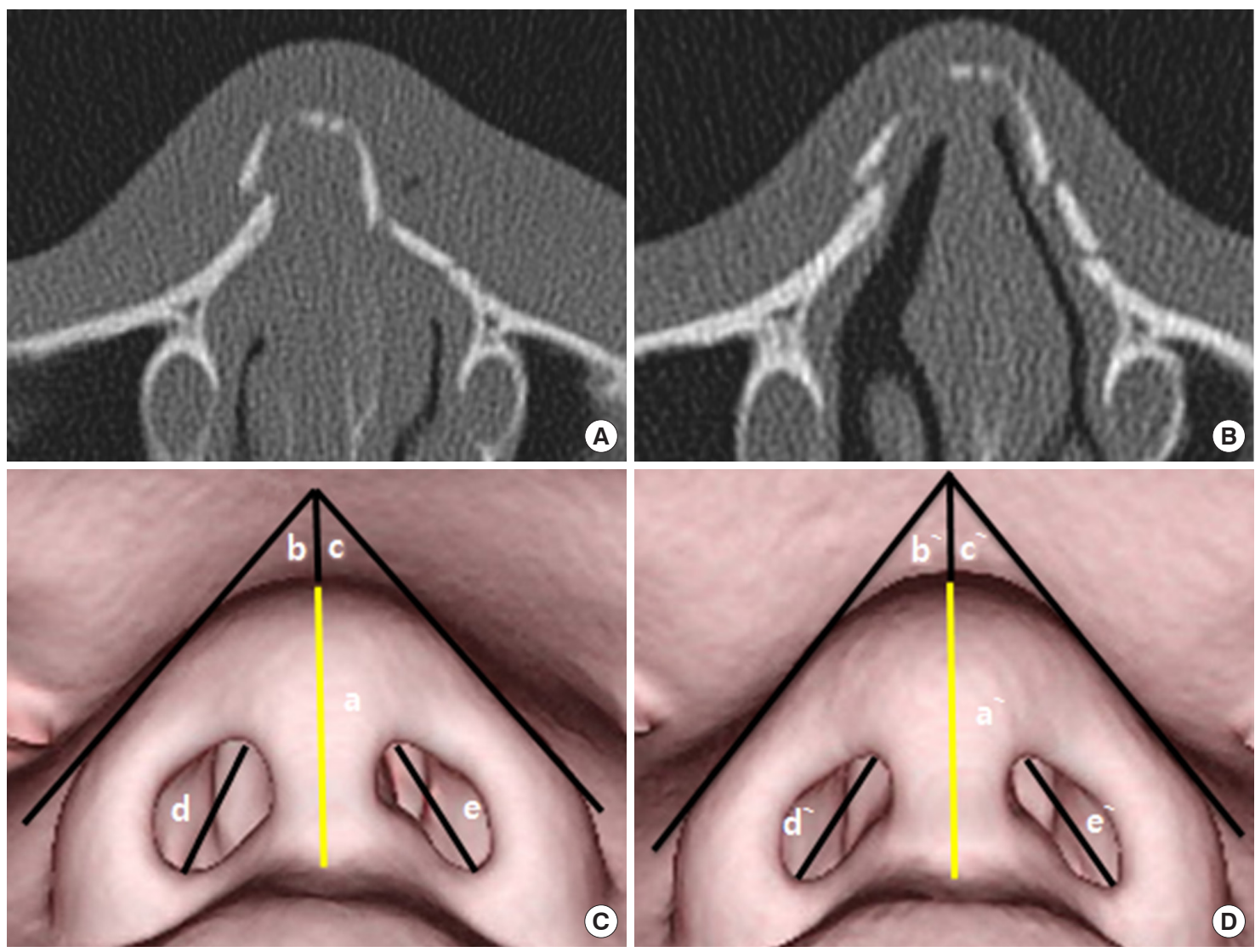

Fig. 4. Three-dimensional (3D) reformation of computed tomography (CT) scan image (base view). (A) Preoperative CT scan. (B) Postoperative CT scan. Preoperative CT and 3D reformation images showing a depression in the left nasal wall and nasal deviation to the right side. (C, D) Postoperative CT and 3D images show good reduction and malalignment with one segment displacement of bone with the soft tissue profile. a, preoperative nasal height: $21.12 \mathrm{~mm}$; a', postoperative nasal height: $22.03 \mathrm{~mm}$; b, preoperative right nasal alar angle: $45.02^{\circ}$; b', postoperative right nasal alar angle: $43.20^{\circ}$; c, preoperative left nasal alar angle: $44.06^{\circ}$; c', postoperative left nasal alar angle: $42.53^{\circ}$; $d$, preoperative long nostril length of right side: $10.10 \mathrm{~mm}$; d', postoperative long nostril length of right side: $10.65 \mathrm{~mm}$; e, preoperative long nostril length of left side: $10.62 \mathrm{~mm}$; e', postoperative long nostril length of left side: $11.10 \mathrm{~mm}$. Length difference between right and left side of the long nostril axis after surgery was $0.45 \mathrm{~mm}$ than $0.52 \mathrm{~mm}$ preoperatively. Deviation of nasal alar angle between right and left side was $1.82^{\circ}$, preoperatively and $1.53^{\circ}$, postoperatively.
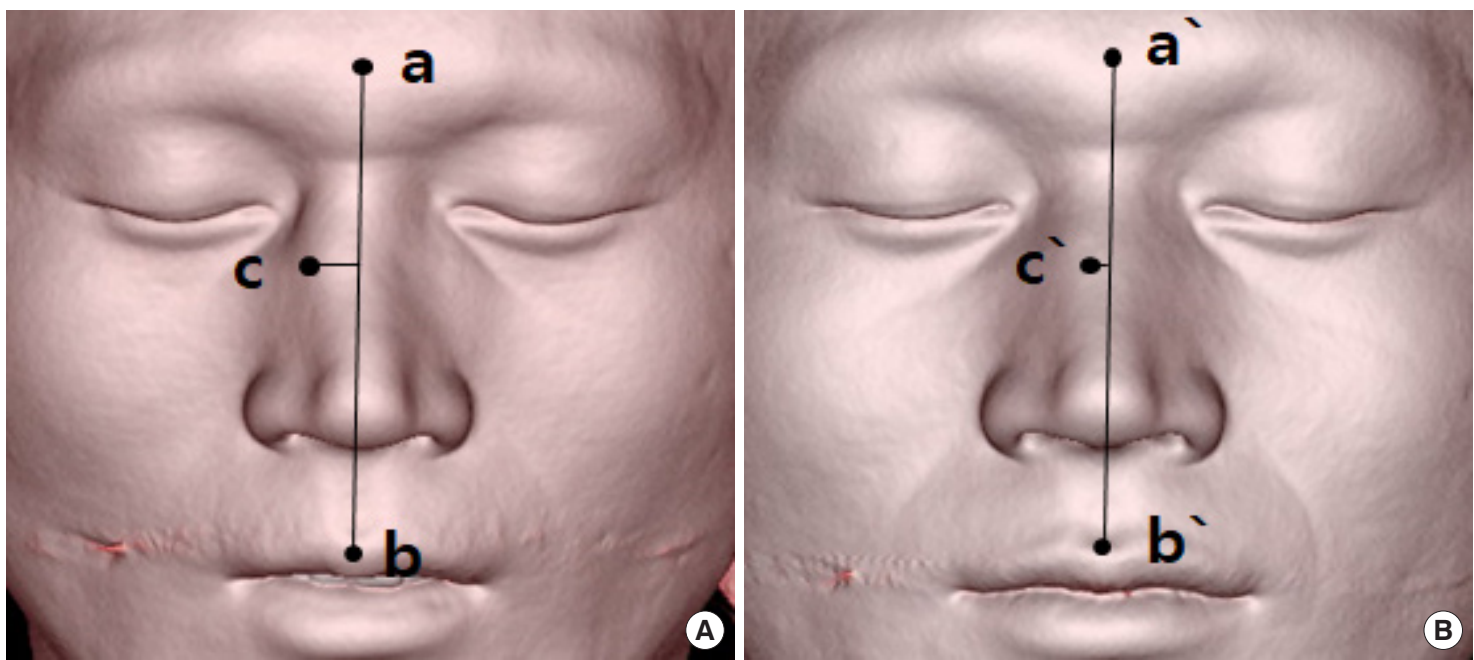

Fig. 5. Three-dimensional (3D) reformation of computed tomography (CT) scan image (frontal view). Preoperative 3D reformation of CT image (A) and postoperative CT image (B). Amount of nasal deviation was $6.820 \mathrm{~mm}$ preoperatively and $0.895 \mathrm{~mm}$ postoperatively. a, a', glabella; b, b', mid point of the upper lip; c, $\mathrm{C}^{\prime}$, most prominent point of deviation. 
formed, this study used nasal photogrammetric anthropometric measurements to evaluate how much external nasal shapes change following nasal operations.

For the height of nasal base, a mean value change of 1.192 $\mathrm{mm}$ was observed (Table 1). The differences in diagonal nostril length between both sides were $0.333 \mathrm{~mm}$ preoperatively and $0.323 \mathrm{~mm}$ postoperatively. The changed amount after operation was $0.010 \mathrm{~mm}$ (Table 2). The deviations of both nasal alar angles were $1.382^{\circ}$ preoperatively and $1.043^{\circ}$ postoperatively. The correction amount was $0.339^{\circ}$ (Table 3 ).

We also evaluated external nasal deviation by measuring amount of dorsal deviation and found how much nasal deviation was corrected after operation. The mean preoperative amount of nasal deviation was $5.248 \mathrm{~mm}$, and the mean postoperative deviation was $1.024 \mathrm{~mm}$. The mean correction value of nasal deviation was $4.224 \mathrm{~mm}$.

The residual deviation of the nasal dorsum after operation was not found to be significant, but acceptable. These results show that changes to nasal dimension after reduction operation were more noticeable in terms of nasal deviation and less noticeable in nasal tip, except for alterations in nasal alar angles between both sides (Figs. 4, 5). However, these results may be considered inaccurate due to nasal swelling discrepancies resulting from patient variations from the time of injury to the time of the operation.

Since the surgeries were performed approximately a week after trauma and the CT scans was examined on the day of surgery, it is thought that there were gaps of about a week between the preoperative and postoperative comparisons of CT images, resulting in a discrepancy in the state of nasal swelling between patients.

Even though the postoperative CT scans were examined the day of surgery, the nose tended to be less swollen after the procedure than in the preoperative state. Therefore, 3D reformations and objective measurements could be useful in evaluating both preoperative and postoperative nasal shape even before in period of stabilization after a sufficient period of time after surgery. Further, nasal shape improvements following nasal bone fracture surgeries were noted through changes in the nasal dorsal deviation and in the nasal alar angle between both sides.

In summary, it can be seen that after reduction procedures, changes in nasal dimensions were noticeable in terms of nasal deviation and less significant in nasal tip, except for changes in the nasal alar angle. This study may be useful when consulting with patients who have experienced nasal bone fractures and need surgical treatment.

\section{NOTES}

\section{Conflict of interest}

No potential conflict of interest relevant to this article was reported.

\section{Ethical approval}

The study was performed in accordance with the principles of the Declaration of Helsinki. Written informed consent was obtained.

\section{Patient consent}

The patients provided written informed consent for the publication and the use of their images.

\section{ORCID}

Seung Bin Jang ～https://orcid.org/0000-0002-1465-6073

Dong Gil Han https://orcid.org/0000-0001-7922-5859

\section{REFERENCES}

1. Oh HK, Park YJ, Kim HS, Ryu JY, Kook MS, Park HJ, et al. A recent 5-year retrospective study on nasal bone fracture. J Korean Assoc Oral Maxillofac Surg 2008;34:230-6.

2. Chung SH, Park JI, Choe J, Baek SM. Clinical analysis of satisfaction of nasal bone reduction. J Korean Soc Plast Reconstr Surg 1994;21:984-90.

3. Hong SB, Choi BW, Suh IS, Ha JH. Clinical \& radiological evaluation of the nasal bone fractures. J Korean Soc Plast Reconstr Surg 1996;23:1572-82.

4. Lee JH, Park WY, Nam HJ, Kim YH. Complications of the nasal bone fractures according to the Stranc classification. J Korean Cleft Palate Craniofac Assoc 2008;9:62-6.

5. Hwang TS, Kang HS. Morphometry of nasal bases and nostrils in Koreans. Ann Anat 2003;185:189-93.

6. Lee HK, Tark KC, Lee YH, Lew JD. Somatometric and anatomic study on nose of Korean women. J Korean Soc Plast Reconstr Surg 1987;14:323-30.

7. Han KH, Kim SJ, Kang JS. A somatometric study of the Korean nose. J Korean Soc Plast Reconstr Surg 1982;9:1-6.

8. Bae TH, Yu Y, Kim WS, Kim HK. Anthropometry of nose in Korean twenties. J Korean Cleft Palate Craniofac Assoc 2009; 10:61-6.

9. Han DG, Kim TS. The effect of half day nasal packing in results of closed reduction of nasal bone fracture. Arch Craniofac Surg 2012;13:119-24.

10. Okur E, Yildirim I, Aydogan B, Akif Kilic M. Outcome of surgery for crooked nose: an objective method of evaluation. Aes- 
thetic Plast Surg 2004;28:203-7.

11. Kwon HJ, Han KH, Kim JH, Son DG. Photogrammetry based on standardized clinical photography using cephalostat: comparison with anthropometric analysis. J Korean Soc Plast Reconstr Surg 2007;34:24-36.

12. Mendonca DA, Naidoo SD, Skolnick G, Skladman R, Woo AS. Comparative study of cranial anthropometric measurement by traditional calipers to computed tomography and three-dimensional photogrammetry. J Craniofac Surg 2013;24:110610.

13. Dindaroglu F, Kutlu P, Duran GS, Gorgulu S, Aslan E. Accuracy and reliability of 3D stereophotogrammetry: a comparison to direct anthropometry and 2D photogrammetry. Angle Orthod 2016;86:487-94. 